KONSTRUKTIVISME, Vol. 8, No. 1, Januari 2016

p-ISSN: 1979-9438, e-ISSN: 2445-2355

FKIP Universitas Islam Balitar, Blitar

Web: konstruktivisme.unisbablitar.ejournal.web.id

\title{
KEMAMPUAN MAHASISWA PPL MERUMUSKAN \\ TUJUAN PEMBELAJARAN PADA MATERI SMA/MA KELAS X
}

\author{
Devita Sulistiana \\ Jurusan Pendidikan Biologi \\ Universitas Islam Balitar \\ Jl. Mojopahit No. 4 Blitar \\ Email: devitasulistiana17@gmail.com
}

\begin{abstract}
This study is aimed at seeing formulation of Specific Instructional Objectives (SIO) developed in the sciences materials by students conducting teaching practice at SMA. This study used descriptive design and assigned subjects of the whole students from Biology Department of UNISBA year 2012/2013. Data of the study included: (1) SIO and its characteristics of its elements: compehensiveness, appropriateness, specification, and attainment, (2) organization of the SIO referring to $A B C D$, audience, behavior, condition, degree. The study found that SIO that is appropriate to the criteria are: (1) appropriate to the good criteria 58.04\% (good), (2) appropriate to the elements of SIO is $98.34 \%$, and (3) appropriate structure regarding level II is $72.32 \%$ good, and $23.66 \%$ fair.
\end{abstract}

Key-words: instructional objective, biology students, sciences.

\begin{abstract}
Abstrak
Penelitian ini bertujuan mengevaluasi rumusan Tujuan Instruktional Khusus (TIK) pada materi IPA yang dikembangkan oleh mahasiswa PPL. Penelitian menggunakan rancangan deskriptif dengan objek penelitian rumusan TIK. Data penelitian ialah rumusan TIK yang disusun oleh mahasiswa PPL Pendidikan Biologi di SMA/MA Semester Genap Tahun Pelajaran 2012/2013 yang mencakup: 1) kriteria TIK meliputi kelengkapan unsur TIK, keseluruhan, kesesuaian, kekhususan, ketercapaian, 2) Unsur dalam merumuskan TIK meliputi adanya ABCD, yaitu audience, behavior, condition, degree. Penelitian menemukan bahwa (1) rumusan TIK yang sesuai dengan kriteria TIK ialah baik (58.04\%), (2) rumusan TIK sesuai dengan unsur TIK ialah baik (98,34\%), dan (3) rumusan yang sesuai dengan kelas II ialah baik $72,32 \%$ dan cukup $23,66 \%$.
\end{abstract}

Kata kunci: Tujuan Instruksional Khusus, Mahasiswa Pendidikan Biologi 
KONSTRUKTIVISME, Vol. 8, No. 1, Januari 2016

p-ISSN: 1979-9438, e-ISSN: 2445-2355

FKIP Universitas Islam Balitar, Blitar

Web: konstruktivisme.unisbablitar.ejournal.web.id

Program studi Pendidikan Pendidikan BiologiFKIP UNISBA merupakan salah satu lembaga pendidikan yang salah satu tugasnya adalah menghasilkan calon guru Pendidikan Biologi yang berdedikasi, benar-benar setia pada profesi dan paham benar dengan tugas serta kewajiban seorang guru. Bagi mahasiswa Pendidikan Biologi FKIP UNISBA pengalaman dalam hal mengajar secara teori diperoleh dalam perkuliahan pengantar pendidikan, perkembangan peserta didik, belajar dan pembelajaran, strategi belajar mengajar, evaluasi proses belajar, telaah kurikulum dan secara praktisnya pada saat PPL.

Program Pengalaman Lapangan (PPL) umumnya disebut praktek mengajar, wajib dilakukan oleh mahasiswa yang akan melaksanakan kuliah akhir di FKIP UNISBA. Sebetulnya PPL bukan hanya praktek mengajar saja, tetapi mencakup semua kegiatan guru di sekolah. Menurut Zulkifli (1998) secara definitif PPL merupakan salah satu kegiatan intrakulikuler yang dilaksanakan FKIP UNISBA yang mencakup kegiatan latihan atau praktek mengajar atau tugas-tugas kependidikan di sekolah praktikan secara terbimbing dan terpadu untuk memenuhi persyaratan pembentukan profesi kependidikan yang dilaksanakan di SMA/MA di Kota/Kabupaten Blitar.

Seorang guru sangat menentukan keberhasilan pendidikan. Untuk mencapai keberhasilan tersebut seorang guru atau calon guru harus mampu merencanakan atau menentukan pengajaran yang baik, dimana rencana pengajaran merupakan pedoman dalam mengajar. Pedoman ini tertuang dalam Tujuan Instruksional atau Pembelajaran. Tujuan Pembelajaran tersebut meliputi TIU (Tujuan Instruksional Umum) dan TIK (Tujuan Instruksional Khusus).

Menurut Mager (dalam Nur'aini, 2011) tujuan adalah suatu deskripsi suatu kinerja yang guru ingin peserta didik dapat tampil sebelum pendidik menganggap peserta didik kompeten. Sebuah tujuan menggambarkan hasil yang diinginkan dari pembelajaran. Tujuan pada pengertian ini adalah sesuatu yang telah dikuasai oleh siswa dan diketahui oleh pendidik yang mentransfer kemampuan tersebut. Sesuatu yang dapat dikuasai ini adalah sesuatu yang dapat dilakukan dan ditunjukkan oleh siswa setelah adanya pembelajaran dengan bimbingan guru, atau berupa suatu hasil belajar kearah yang positif.

TIK merupakan hasil penjabaran dari TIU dalam bentuk perilaku spesifik. Dengan kata lain dapat disebutkan bahwa TIK adalah kumpulan dari pernyataan yang lebih sempit dan terinci dibandingkan TIU yang biasanya dinyatakan dengan kata kerja yang operasional, sehingga memudahkan pengajar dalam mengukur hasil belajar. Dalam proses pembuatan TIK rincian pernyataannya didasarkan pada TIU. TIU dapat dilihat dari GBPP, sedangkan TIK harus dirumuskan sendiri oleh guru mata pelajaran yang bersangkutan berdasarkan TIU berisi sejumlah kemampuan yang lebih spesifik yang dijabarkan dalam bahan atau materi ajar untuk menunjang pencapaian kemampuan yang terkandung dalam TIU.

Guru berkewajiban merumuskan TIK sebelum pembelajaran dimulai, karena TIK merupakan tujuan mendasar yang menunjang tercapainya tujuan pembelajaran umum, tujuan kurikuler, tujuan instruksional dan akhirnya sampai pada tujuan Pendidikan Nasional. Guru 
dan calon guru harus tahu merumuskan TIK yang baik. TIK harus mempunyai komponen yang merupakan syarat agar dapat digunakan dalam proses belajar mengajar. Menurut Slameto (1991) TIK adalah indikator dalam bentuk yang lengkap. Kriteria TIK yang baik mengandung kelengkapan Unsur TIK, kriteria, kejelasan, kesesuaian, kekhususan. Knirk dan Gustafson (dalam Nita, 2011) menyatakan ada empat komponen yang harus ada dalam rumusan tujuan, yang oleh Institusi Pengembangan Pembelajaran dikenal dengan Format ABCD, yaitu Audiens, Behavior, Condition, dan Degree. Perumusan TIK berpedoman kepada GBPP dan buku paket.

Dalam pelaksanaan PPL bagi mahasisiwa Pendidiakan Pendidikan Biologi Semester Genap Tahun Akademik 2012/2013 yang dilaksanakan pada tanggal 11 Februari sampai dengan 16 Maret 2014. Berdasarkan observasi awal masih terdapat kesenjangan-kesenjangan dimana apa yang diharapkan belumlah dicapai sebagaimana mestinya. Hal ini terlihat dari informasi guru pamong yang membimbing PPL bahwa sebagian besar mahasiswa Pendidikan Pendidikan Biologi belum mampu merumuskan TIK menurut semestinya, belum mampu merencanakan pengajaran yang sesuai dengan materi pengajaran, memilih metoda, menentukan media, perencanaan kegiatan belajar mengajar dan menyusun evaluasi. Ternyata merumuskan TIK bukan merupakan pekerjaan yang mudah. Untuk merumuskan TIK diperlukan keterampilan yang tinggi agar TIK yang dibuat dapat memberikan manfaat bagi siswa tanpa mengesampingkan fungsi sebenarnya TIK yaitu sebagai indikator tercapainya tujuan instruksional.

Berdasarkan hal-hal di atas dalam penelitian ini menganalisis kemampuan mahasiswa Pendidikan Pendidikan Biologi yang PPL tahun akademik 2012/2013 dalam merumuskan TIK pada materi SMA/MA Semester Genap. Sedangkan manfaat penelitian ini adalah untuk memperoleh informasi tentang kemampuan mahasiswa Pendidikan Biologi dalam merumuskan TIK sehingga dapat dijadikan bahan pertimbangan untuk pelaksanaan PPL selanjutnya.

\section{METODE}

Penelitian ini dilaksanakan di FKIP yaitu UPT PPL Islam Balitar pada Bulan Maret sampai April 2014. Penelitian ini merupakan penelitian deskriptif. Sebagai objek penelitian adalah seluruh TIK yang dirumuskan mahasiswa Pendidikan Biologi yang PPL di SMA/MA Semester Genap Tahun Akademik 2012/2013. Jenis data yang digunakan adalah data sekunder berupa TIK yang disusun oleh mahasiswa PPL Pendidikan Biologi di SMA/MA Semester Genap Tahun Pelajaran 2012/2013 yang mencakup: 1) kriteria TIK meliputi kelengkapan unsur TIK, kriteria keseluruhan, kriteria kesesuaian, kriteria kekhususan, kriteria ketercapaian, 2) Unsur dalam merumuskan TIK meliputi adanya ABCD, yaitu audience, behavior, condition, degree. Data dianalisis secara deskriptif dengan mencari persentase selanjutnya kemampuan mahasiswa dalam menyusun TIK dikelompokkan dalam kategori skala Likert seperti Tabel 1 berikut: 
Tabel 1. Kategori Penilaian TIK berdasarkan Persentase

\begin{tabular}{ccc}
\hline No. & Persentase & Kriteria \\
\hline 1 & $>70 \%$ & Sangat Baik \\
2 & $31-70 \%$ & Baik \\
3 & $16-30 \%$ & Cukup \\
4 & $5-15 \%$ & Kurang \\
5 & $<5 \%$ & Sangat Kurang \\
\hline
\end{tabular}

Tabel 2. Komponen Kriteria yang Dinilai dalam Penyusunan TIK

\begin{tabular}{cl}
\hline No. & Komponen \\
\hline 1 & Kelengkapan \\
2 & Keseluruhan \\
3 & Kesesuaian \\
4 & Kekhususan \\
5 & Ketercapaian \\
\hline
\end{tabular}

Tabel 3. Unsur-Unsur yang Harus Dipenuhi dalam Perumusan TIK

\begin{tabular}{cc}
\hline No. & Unsur \\
\hline 1 & Audience \\
2 & Behavior \\
3 & Condition \\
4 & Degree \\
\hline
\end{tabular}

\section{HASIL DAN BAHASAN}

Analisis kemampuan mahasiswa Pendidikan Biologi yang PPL dalam merumuskan TIK pada materi SMA/MA kelas X Semester Genap sesuai dengan kriteria TIK dapat dilihat pada Tabel 4, sedangkan kemampuan mahasiswa dalam merumuskan TIK sesuai dengan unsur TIK disajikan dalam Tabel 5.

Tabel 4. Kemampuan Mahasiswa Pendidikan Biologi yang PPL dalam Merumuskan TIK Sesuai dengan Kriteria TIK pada Materi SMA/MA Kelas X Semester Genap Tahun Pelajaran 2013/2014

\begin{tabular}{ccccccc}
\hline No. & $\begin{array}{c}\text { Sebaran Persentase dalam setiap } \\
\text { Kompetensi Dasar }\end{array}$ & \multicolumn{4}{c}{ Jumlah Kriteria TIK Yang Muncul } & \multirow{2}{*}{$\mathrm{N}$} \\
\cline { 2 - 6 } & & 1 & 2 & 3 & 4 & 5 \\
\end{tabular}


FKIP Universitas Islam Balitar, Blitar

Web: konstruktivisme.unisbablitar.ejournal.web.id

\begin{tabular}{|c|c|c|c|c|c|c|c|}
\hline 1 & Komponen Ekosistem & - & 4 & 8 & 32 & 40 & 84 \\
\hline 2 & Hubungan Manusia dengan Ekosistem & - & - & 12 & 16 & 42 & 70 \\
\hline 3 & Jenis-Jenis Limbah & - & - & 8 & 48 & 48 & 70 \\
\hline \multicolumn{2}{|c|}{ Jumlah TIK } & - & 4 & 28 & 62 & 130 & 244 \\
\hline & nlah TIK & - & 1,79 & 12,50 & 27,68 & 58,04 & 100 \\
\hline \multicolumn{2}{|c|}{ Kategori } & - & $\begin{array}{l}\text { Kurang } \\
\text { sekali }\end{array}$ & Kurang & Cukup & Baik & - \\
\hline
\end{tabular}

Keterangan:

1. Hanya 1 kriteria yang muncul

2. Hanya 2 kriteria yang muncul

3. Hanya 3 kriteria yang muncul

4. Hanya 4 kriteria yang muncul

5. Kelima kriteria yang muncul

Tabel 5. Kemampuan Mahasiswa Pendidikan Biologi yang PPL dalam Merumuskan TIK Sesuai dengan Unsur TIK Pada Materi SMA/MA Kelas X Semester Genap Tahun Pelajaran 2013/2014

\begin{tabular}{|c|c|c|c|c|c|c|}
\hline \multirow[t]{2}{*}{ No. } & \multirow[t]{2}{*}{ Sebaran Persentase } & \multicolumn{4}{|c|}{ Jumlah Unsur TIK Yang Muncul } & \multirow{2}{*}{$\mathrm{N}$} \\
\hline & & 1 & 2 & 3 & 4 & \\
\hline 1 & Komponen Ekosistem & - & 2 & 21 & 61 & 84 \\
\hline 2 & Hubungan Manusia dengan & - & 5 & 17 & 48 & 70 \\
\hline 3 & $\begin{array}{l}\text { Ekosistem } \\
\text { Jenis-Jenis Limbah }\end{array}$ & - & 2 & 15 & 53 & 70 \\
\hline \multirow{2}{*}{\multicolumn{2}{|c|}{$\begin{array}{l}\text { Jumlah TIK } \\
\text { Jumlah TIK }\end{array}$}} & - & 9 & 53 & 162 & 224 \\
\hline & Ilah TIK & & 4.02 & 23,66 & 72,32 & 100 \\
\hline \multicolumn{2}{|c|}{ Kategori } & - & Kurang & Cukup & Baik & - \\
\hline
\end{tabular}

Keterangan:

1. Hanya 1 unsur yang muncul

2. Hanya 2 unsur yang muncul

3 . Hanya 3 unsur yang muncul

4. Keempat unsur muncul

Berdasarkan Tabel 4 dan Tabel 5 diketahui bahwa dari 224 rumusan TIK yang disusun oleh 14 mahasiswa Pendidikan Biologi yang PPL di semester genap Tahun Akademik 2013/2014 pada materi kelas X terdapat 130 TIK yang lengkap, dengan memiliki 3 kriteria dengan persentase $27,68 \%$ (kategori cukup), sedangkan TIK yang dinilai masih kurang dengan hanya terdiri dari 3 kriteria yaitu 28 TIK atau 12,50\% dengan kategori kurang dan TIK yang hanya memuat 2 kriteria saja sejumlah 4 TIK atau 1,79\% dengan kategori sangat kurang.

Dari hasil analisis tersebut dapat dikatakan bahwa mahasiswa Pendidikan Biologiyang PPL dalam merumuskan TIK masih ada yang kurang mengerti dan memahami kriteria TIK, sehingga TIK yang dirumuskan ada yang tidak mengandung kelima kriteria TIK. Hal ini terlihat dari 28 TIK yang mengandung 3 kriteria. Sedangkan berdasarkan unsur TIK mahasiswa sebagian besar $(73,32 \%)$ telah mengerti dan memahami dalam merumuskan TIK yang baik sesuai dengan unsur TIK. 
Konstruktivisme, 8(1): 54-60.

Arikunto (1999) mengatakan sesuai dengan tuntutan guru dalammerumuskan TIK harus mengandung apa yang dilakukan dalam kegiatan belajar mengajar, bagaimana menunjukkan kemampuan atau hasilnya dan perolehan hasilnya. Dengan demikian jika perumusan TIK sudah baik dan jelas, maka guru dalam mengajarpun mengetahui batasbatas materi yang akan disampaikan dan siswapun tidak bingung. Pada hakekatnya rumusan TIK yang baik menggambarkan rumusan kemampuan yang diharapkan dapat dimiliki dan dikuasai siswa setelah menempuh proses belajar mengajar.

Hasil analisis kemampuan mahasiswa Pendidikan Biologi yang PPL dalam merumuskan TIK pada materi SMA/MA kelas X Semester Genap sesuai dengan kriteria dan unsur TIK dapat dilihat pada tabel 4 dan tabel 5. Berdasarkan tabel 4 dan 5 diketahui bahwadari 224 TIK yang disusun oleh mahasiswa Pendidikan Biologi pada materi kelas X Semester Genap diperoleh 130 TIK atau lebih dari separo TIK yang dibuat lengkap memiliki 5 kriteria dengan prosesntase $58,04 \%$ (kategori baik), sementara itu sejumlah 160 TIK dari 224 TIK atau 72,32\% TIK telah memiliki keempat unsur ABCD (audience, behavio, condition, degree). Hal ini dapat dikatakan bahwa mahasiswa Pendidikan Biologi telah mengerti dan memahami bagaimana merumuskan TIK yang sesuai dengan kriteria dan unsur TIK yang baik dan benar. Rumusan TIK yang baik beorientasi pada siswa bersifat menguraikan hasil belajar, jelas dan dapat dimengerti serta dapat diukur.

Hasil analisis kemampuan mahasiswa Pendidikan Biologi yang PPL dalam merumuskan TIK pada materi SMA/MA kelas X Semester Genap sesuai dengan kriteria dan unsur TIK dapat dilihat pada tabel 5 dan 6 dirasa sudah berhasil, namun demikian perlu bimbingan lagi dalam hal teknik penyusunan TIK untuk perbaikan pelaksanaan PPL di tahun mendatang, karena bagaimanapun juga keberhasilan guru dalam merumuskan TIK akan menjadi kualitas guru dalam pembelajaran. Hal ini sesuai dengan yang disampaikan Ibrahim (1996) yang mengatakan bahwa keberhasilan seorang guru dalam mengajar dapat diukur dari sejauh mana tujuan pembelajaran yang dirumuskan dapat tercapai.

Dalam rumusanTIK seharusnya dipilih metode apa yang cocok untuk kondisi materi tersebut agar dapat diukur sejauh mana pembelajaran berhasil dengan tuntas. Penguasaan materi pelajaran juga menentukan kemampuan mahasiswa dalam merumuskan TIK. Semakin tinggi tingkatan kelas semakin sulit materi pembelajarannya, untuk itu diperlukan keseriusan mahasiswa itu sendiri dalam memahami dan menguasainya sebelum mengajar. Penguasaan materi perlu dalam merumuskan TIK karena bila materi telah dikuasai maka akan mudah menuangkannya dalam bentuk TIK yang merupakan rumusan tujuan yang ingin dicapai dalam proses belajar mengajar.

Ibrahim dan Syaddin (1996), menyatakan bahwa di dalam menetapkan materi pelajaran hendaknya memperhatikan beberapa hal antara lain, materi pelajaran hendaknya dapat menunjang tercapainya TIK, sesuai dengan tingkat perkembangan siswa, terorganisasi secara sistematis dan berkesinambungan sehingga dapat memberikan umpan balik pada TIK yang dirumuskan. Tujuan instruksional dapat menjadi arah 
proses pengembangan instruksional karena di dalamnya tercantum rumusan pengetahuan, keterampilan dan sikap yang akan dicapai siswa pada akhir proses instruksional. Keberhasilan siswa dalam mencapai tujuan tersebut merupakan ukuran keberhasilan sistem instruksional yang digunakan oleh pengajar. Guru akan mengajar efektif apabila selalu membuat perencanaan berupa TIK sebelum mengajar. Dengan persiapan mengajar guru akan mantap berada di depan kelas, perencanaan yang matang dapat menimbulkan inisiatif dan meningkatkan daya kreasi guru sewaktu mengajar, sehingga interaksi mengajar antara guru dan siswa dapat meningkat.

\section{SIMPULAN}

Mahasiswa Pendidikan Biologi FKIP UNISBA yang PPL tahun pelajaran 2013/2013 dalam merumuskan TIK sesuai dengan kriteria TIK pada materi SMA/MA kelas X Semester Genap Tahun Pelajaran 2013/2014 berada pada kategori baik (58.04\%), sedangkan perumusan TIK sesuai dengan unsur TIK pada materi SMA/MA kelas X Semester Genap berada pada kategori baik $(98,34 \%)$, di kelas II Semester Genap dengan kategori baik $72,32 \%$ dan cukup $23,66 \%$.

\section{DAFTAR PUSTAKA}

Arief. 1986. Prosedur Pengembangan SistemInstruksional dan

Penerapannya Dalam MenyusunModel Satuan Pelajaran. Jakarta:

Badan Pengembangan Pendidikan.

Budiharso, Teguh. 2015. Teaching Practice: Does It Substantiate

Teacher's Profession Development?. Pedagogik, 8(1): 34-46. www.jurnal-pedagogik.info.

Harjanto. 1997. Perencanaan Pengajaran. Jakarta: Rineka Cipta.

Ibrahim dan Syaddin, N. 1996. PerencanaanPengajaran. Jakarta: Rineka Cipta.

Kadir, A. 1981. Pedoman Mengajar Bimbingan PraktekUntuk Calon Guru. Surabaya: Al lkhlas.

Mudhoffir. 1986. Teknologi Instruksional. Jakarta: Penerbit P.T Remaja.

Slameto. 1991. Belajar dan Faktor-faktor yang Mempengaruhi. Jakarta: Bina Aksara.

Solikhah, Imroatus. 2014. Instructional Design in English Lesson Plans. Lingua, 11(1): 35-47. www.jurnal-lingua.info.

Solikhah, Imroatus. 2015. KKNI dalam Kurikulum Berbasis Learning Outcomes. Lingua, 12(1): 1-22. www.jurnal-lingua.info.

Suryosubroto. 1997. Proses Belajar Mengajar di Sekolah. Jakarta: Rineka Cipta. 